\title{
A Two-Level Undercut-Profile Substrate for Chemical-Solution-Based Filamentary Coated Conductors
}

Wulff, Anders Christian; Lundeman, Jesper H.; Hansen, Jørn B.; Mishin, Oleg; Yue, Zhao; Mohajeri, Roya; Grivel, Jean-Claude

Published in:

I E E E Transactions on Applied Superconductivity

Link to article, DOI:

10.1109/TASC.2016.2536938

Publication date:

2016

Document Version

Peer reviewed version

Link back to DTU Orbit

Citation (APA):

Wulff, A. C., Lundeman, J. H., Hansen, J. B., Mishin, O., Yue, Z., Mohajeri, R., \& Grivel, J-C. (2016). A Two-

Level Undercut-Profile Substrate for Chemical-Solution-Based Filamentary Coated Conductors. I $E E$

Transactions on Applied Superconductivity, 26(3), [6601604]. https://doi.org/10.1109/TASC.2016.2536938

\section{General rights}

Copyright and moral rights for the publications made accessible in the public portal are retained by the authors and/or other copyright owners and it is a condition of accessing publications that users recognise and abide by the legal requirements associated with these rights.

- Users may download and print one copy of any publication from the public portal for the purpose of private study or research.

- You may not further distribute the material or use it for any profit-making activity or commercial gain

- You may freely distribute the URL identifying the publication in the public portal 


\title{
A two level undercut-profile substrate for chemical- solution-based filamentary coated conductors
}

\author{
Anders C. Wulff, Jesper H. Lundeman, Jørn B. Hansen, Oleg V. Mishin, Yue Zhao, Roya Mohajeri, Jean-Claude
}

Grivel

\begin{abstract}
A recently developed two level undercut-profile substrate (2LUPS), containing two levels of plateaus connected by a curved wall with an undercut-profile, enables self-forming filaments in a coated conductor during physical line-of-sight deposition of buffer and superconducting layers. In the present study, the 2LUPS concept is applied to a commercial cubetextured Ni-5at.\%W tape, and the surface of the 2LUPS coated with two $\mathrm{Gd}_{2} \mathrm{Zr}_{2} \mathrm{O}_{7}$ buffer layers using chemical solution deposition is examined. Except for narrow regions near the edge of upper plateaus, the plateaus are found to be covered by strongly textured $\mathrm{Gd}_{2} \mathrm{Zr}_{2} \mathrm{O}_{7}$ buffer layers after dip coating and sintering.
\end{abstract}

Index Terms-Superconducting filaments and wires, substrates, etching, texture, scanning electron microscopy

\section{INTRODUCTION}

It is known that filamentization and subsequent transposition of coated conductors (CCs) used in alternating current (AC) power applications, such as generators, motors and fault current limiters, can reduce AC losses [1] - [4]. Transposition of the CCs can be achieved using either the Roebel configuration [5] or the cable on round core configuration [6]. However, when filaments are produced by mechanical scribing, laser striation and etching processes applied to the rare-earth barium-copperoxide (REBCO) superconducting layer [7] - [9], the currentcarrying width of the CCs is also reduced. In addition, these techniques can introduce defects in the REBCO layer. In contrast to these filamentization techniques, a recently introduced two level undercut-profile substrate (2LUPS) concept [10] (Fig. 1) potentially enables full operational width of the superconducting layer and is less vulnerable to defects in the superconducting layer. The 2LUPS concept is based on two levels of plateaus connected by a curved wall with an undercutprofile produced by selective etching of the substrate material [11].

In our previous work on a commercial Hastelloy C276 tape [10] (discussed by Hopkins [12]), such a profile has already been successfully demonstrated to produce a shading effect during subsequent physical line-of-sight deposition of buffer and superconducting layers, which resulted in self-forming filaments in the coated conductor. In the present study, the

Automatically generated dates of receipt and acceptance will be placed here; authors do not produce these dates. This work was supported in part by DTU Energy within the framework of the project "Filamentary coated conductors" (Corresponding author: A. C. Wulff.)

A. C. Wulff, Y. Zhao and J.- C. Grivel are with the Department of Energy Conversion and Storage, Technical University of Denmark, 4000 Roskilde, Denmark.
2LUPS concept is applied to a standard cube-textured Ni5 at.\%W tape which is then coated with two buffer layers using chemical solution deposition (CSD). The processing steps are schematically illustrated in Fig. 1a,b which shows a 2LUPS before and after coating with buffer layers. The new substrate and subsequently deposited $\mathrm{Gd}_{2} \mathrm{Zr}_{2} \mathrm{O}_{7}(\mathrm{GZO})$ buffer layers are characterized using scanning electron microscopy (SEM), electron backscatter diffraction (EBSD) and X-ray diffraction (XRD) techniques. The tape after deposition of REBCO layers using a line-of-sight process shown in Fig. 1(c) has not been analyzed yet. Therefore, the quality of the REBCO layers deposited on this Ni-5at.\%W 2LUPS is not considered in the present communication.
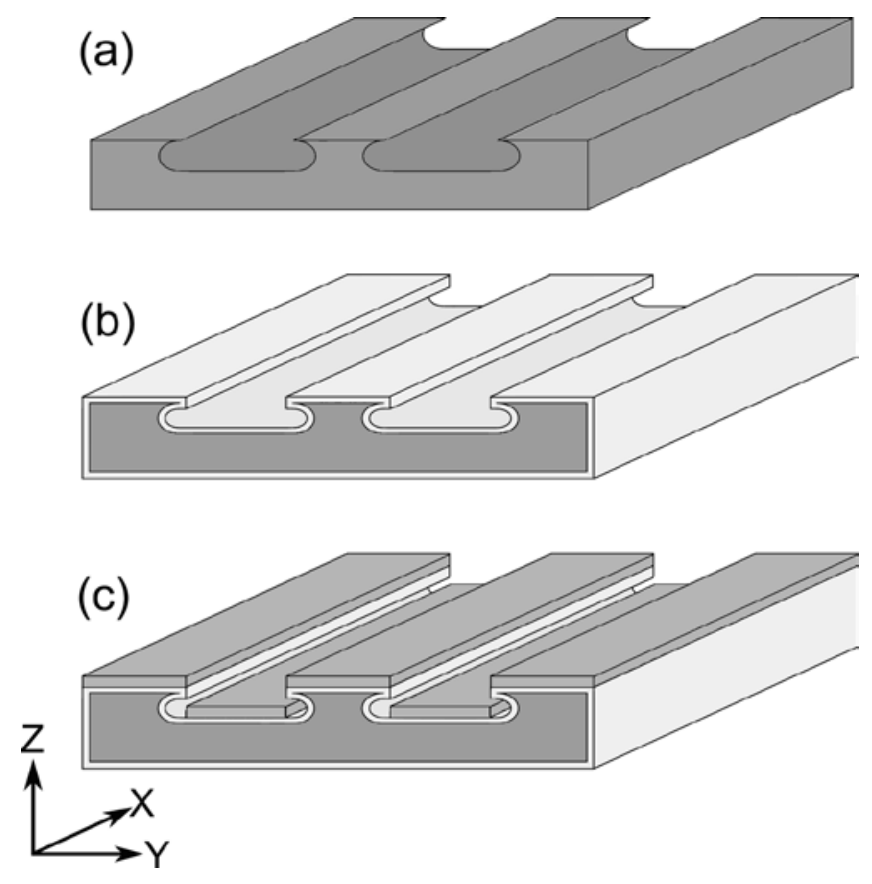

Fig. 1. Schematic illustration of 2LUPS filamentary CC processing: (a) 2LUPS; (b) 2LUPS coated with a chemical-solution-based buffer layer; (c) 2LUPS with the buffer layer and a superconducting REBCO layer coated using a line-of-sight process.

J. H. Lundeman and J. B. Hansen are with SUBRA IVS, 2765 Smørum, Denmark.

O. V. Mishin is with the Department of Wind Energy, Technical University of Denmark, 4000 Roskilde, Denmark.

R. Mohajeri is with the Department of Electrical Engineering, Sharif University of Technology, Tehran, Iran. 


\section{EXPERIMENTAL}

A strongly cube-textured commercial $\mathrm{Ni}-5 \mathrm{at} . \% \mathrm{~W}$ tape $\left(\mathrm{L} \times \mathrm{W} \times \mathrm{T}=100 \times 10 \times 0.7 \mathrm{~mm}^{3}\right)$ from Evico $\mathrm{GmbH}$ was used in this work for manufacturing a 2LUPS. Protective adhesive film strips were applied parallel to the tape rolling direction and subsequently cut in a reel-to-reel system in order to divide the film into three strips across the width. The center strip was peeled off to enable etching in the unprotected area of the tape. The tape was first etched at $50^{\circ} \mathrm{C}$ in a $\mathrm{H}_{2} \mathrm{SO}_{4} / \mathrm{H}_{3} \mathrm{PO}_{4}$-based electrolyte, thus producing etched tracks, and then cleaned in water (see [11] for more details). The tape was then additionally etched in a $\mathrm{H}_{2} \mathrm{SO}_{4} / \mathrm{H}_{2} \mathrm{O}$-based electrolyte to obtain a smooth surface of the etched tracks [11], after which the protective film was peeled off also from the unetched tracks. Finally, the tape was heat treated at $850^{\circ} \mathrm{C}$ in a flow of $\mathrm{N}_{2} / 5 \% \mathrm{H}_{2}$ for $30 \mathrm{~min}$ to remove the oxide layer. Two GZO buffer layers were produced by dip coating in a precursor solution [13] with a total cationic concentration of $0.6 \mathrm{~mol} / \mathrm{L}$ and using a tape withdrawal speed of $20 \mathrm{~mm} / \mathrm{min}$. The coated films were sintered at $1125^{\circ} \mathrm{C}$ in a flow of $\mathrm{N}_{2} / 5 \% \mathrm{H}_{2}$ for $30 \mathrm{~min}$.

A Leitz Aristomet optical microscope was used for investigating the sample cross-section. The sample surface coated with two GZO layers was investigated in a Carl Zeiss 1540 XB scanning electron microscope. Phase analysis of the GZO layers was conducted using a Bruker D8 $\mathrm{X}$-ray diffractometer with a $\mathrm{Cu} \mathrm{K} \alpha$ source. The XRD measurements were performed masking either upper or lower plateaus to enable a separate analysis of the different plateaus.

Crystallographic orientations of the sample coated with two GZO layers were measured using the EBSD technique in a field emission gun electron microscope Zeiss Supra 35 equipped with Channel 5 software from HKL Technology. A total area of $\sim 34 \mathrm{~mm}^{2}$ was investigated with a step size of $15 \mu \mathrm{m}$ in the rolling plane covering both lower and upper plateaus.

\section{RESULTS AND DISCUSSION}

Fig. 2a demonstrates the cross-section of the Ni-5at.\%W 2LUPS where upper and lower plateaus are clearly seen. The undercut length L (Fig. 2b) in this 2LUPS is $2.3 \mu \mathrm{m}$, which is greater than that $(\mathrm{L}=0.3 \mu \mathrm{m})$ in our previous work on Hastelloy C276 [10]. This increase is achieved by improving the adhesion between the metal tape and the protective film.

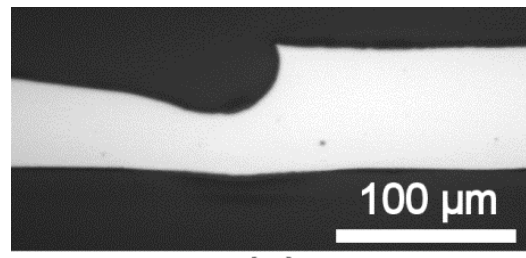

(a)

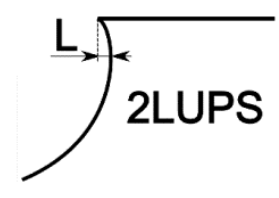

(b)
Fig. 2. (a) an optical micrograph from the cross-section of the Ni-5at.\%W 2LUPS; (b) definition of the undercut length.

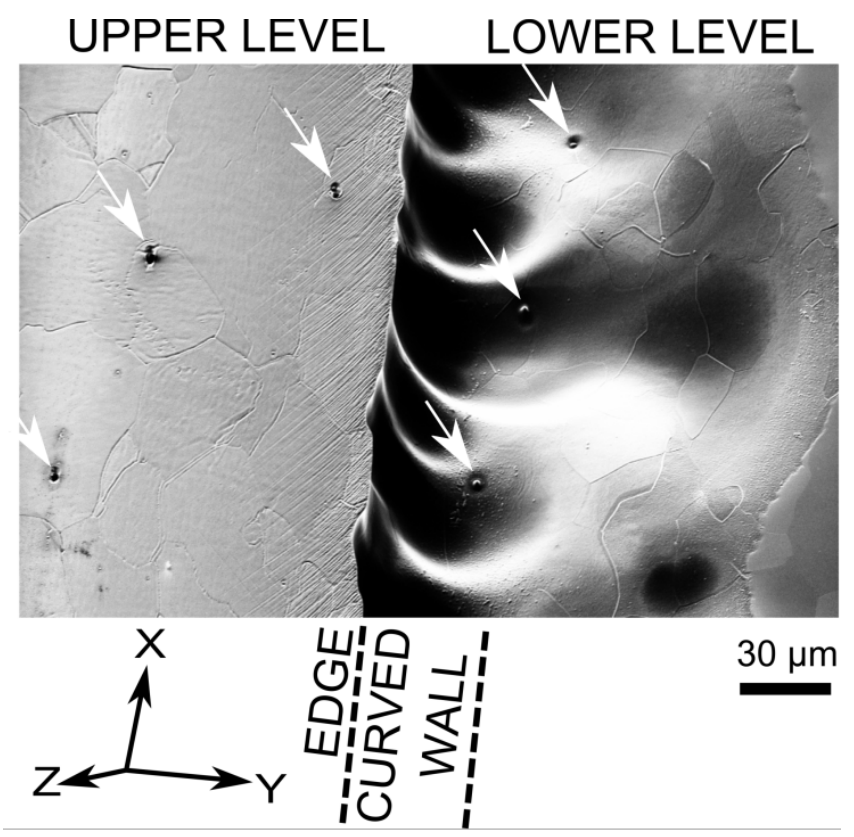

Fig. 3. SEM image from a region near the wall of the Ni-5at.\%W 2LUPS coated with two GZO layers. The image was taken after tilting the sample $55^{\circ}$ about the Y axis. Arrows indicate small pin-like defects.

The plateau regions near the wall and part of the curved wall between the two levels of the 2LUPS sample coated with two GZO layers are shown in Fig. 3. Grain boundary grooves seen on the plateau surface are a result of significant thermal etching occurring during the high-temperature sintering of the buffer layers [13], [14]. The surface also contains a few small defects (indicated by arrows in Fig. 3), most likely originating from the $\mathrm{Ni}-5$ at.\%W tape. In addition, slip lines [15] are observed near the edge of the upper plateau (see also Fig. 4a). The lines are very pronounced at the edge and gradually diminish within a distance of $\sim 50 \mu \mathrm{m}$ from the edge. These slip lines are apparently induced by deformation during cutting. Fig. 4b provides evidence that the rough surface containing these lines is not fully covered by GZO. Therefore, such areas will not prevent $\mathrm{Ni}$ diffusion [16] and are not expected to enable appropriate epitaxial growth of the REBCO layer [17]. It is suggested that formation of the slip lines near the edges can be prevented if cutting is conducted in the hard as-rolled (not annealed) condition. In this case, the cube texture will be produced by annealing of the 2LUPS after cutting and etching.

The curved wall appears to have waves along the length of the substrate (see Fig. 3), which can be due to excessive oxygen produced during the etching processes [18]. The waves extend to the lower plateau covering a width of approximately $130 \mu \mathrm{m}$. It is expected that the waviness can be significantly reduced by improved control of oxygen formation during the etching processes. 

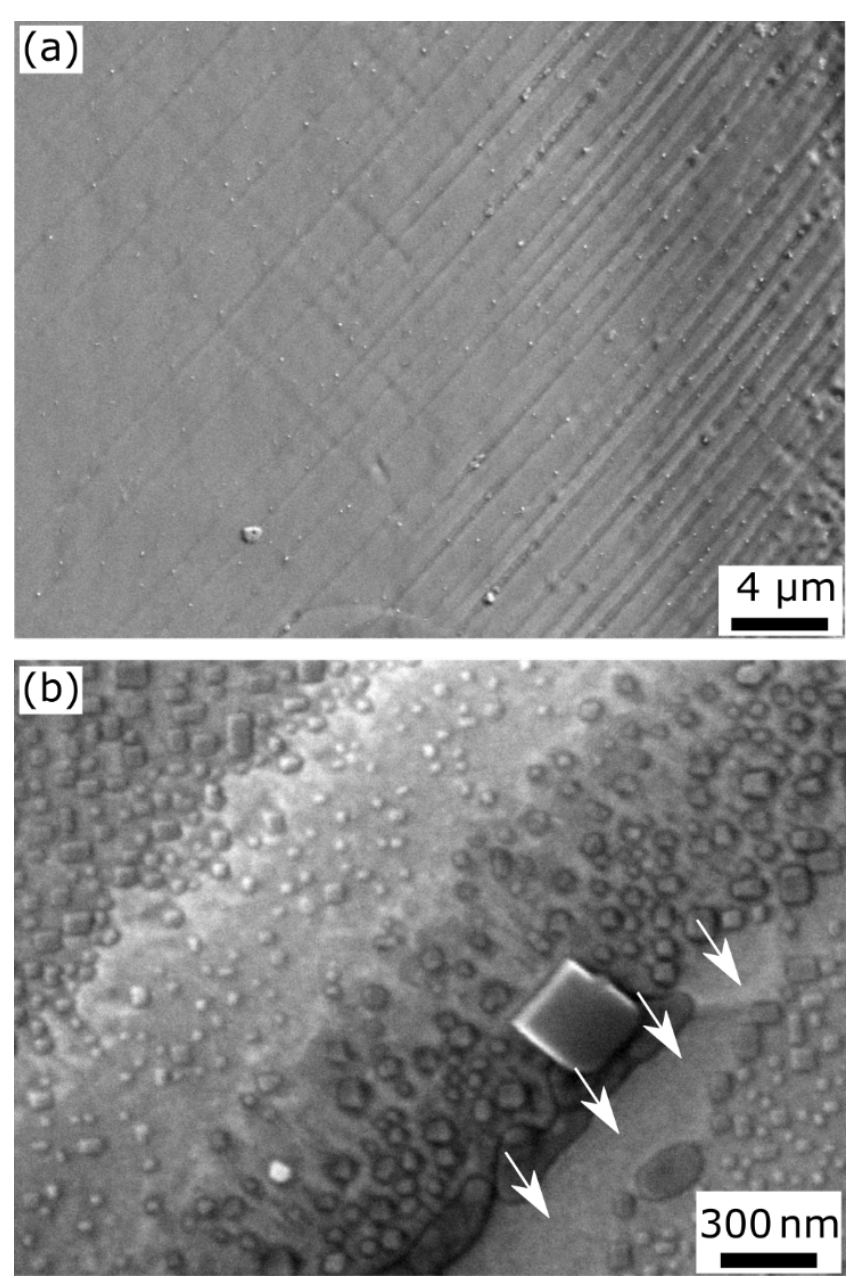

Fig. 4. SEM images taken near the edge of the upper plateau of the Ni-5at.\%W 2LUPS coated with two GZO layers: (a) low magnification image; (b) high magnification image A region not covered by GZO is marked by arrows in (b).

Fig. 5 shows that the GZO layers on the filament body are dense, homogeneous and crack-free. Comparing grain structures in the GZO layers on the different plateaus, it appears that their morphologies are slightly different, i.e., the grains on the upper plateau are more rectangular than those on the lower plateau (cf. Fig.5a and Fig.5b).

The EBSD data in Fig. 6 indicate that the texture in the GZO layer is characterized by a sharp $\{001\}\langle 110\rangle$ component, i.e. $45^{\circ}$ rotated cube orientation [19]. There is almost no difference in the maximum intensity of this component between the lower and upper plateaus (cf. Fig. 6a and Fig. 6b).

The XRD data from the coated surface (Fig. 7) demonstrate very strong (004) reflections from GZO on each plateau, which is consistent with the EBSD data. In addition, Fig. 7 contains smaller peaks labelled "X", which are artifacts due to tungsten deposited on the $\mathrm{Cu} \mathrm{K} \alpha$ source.
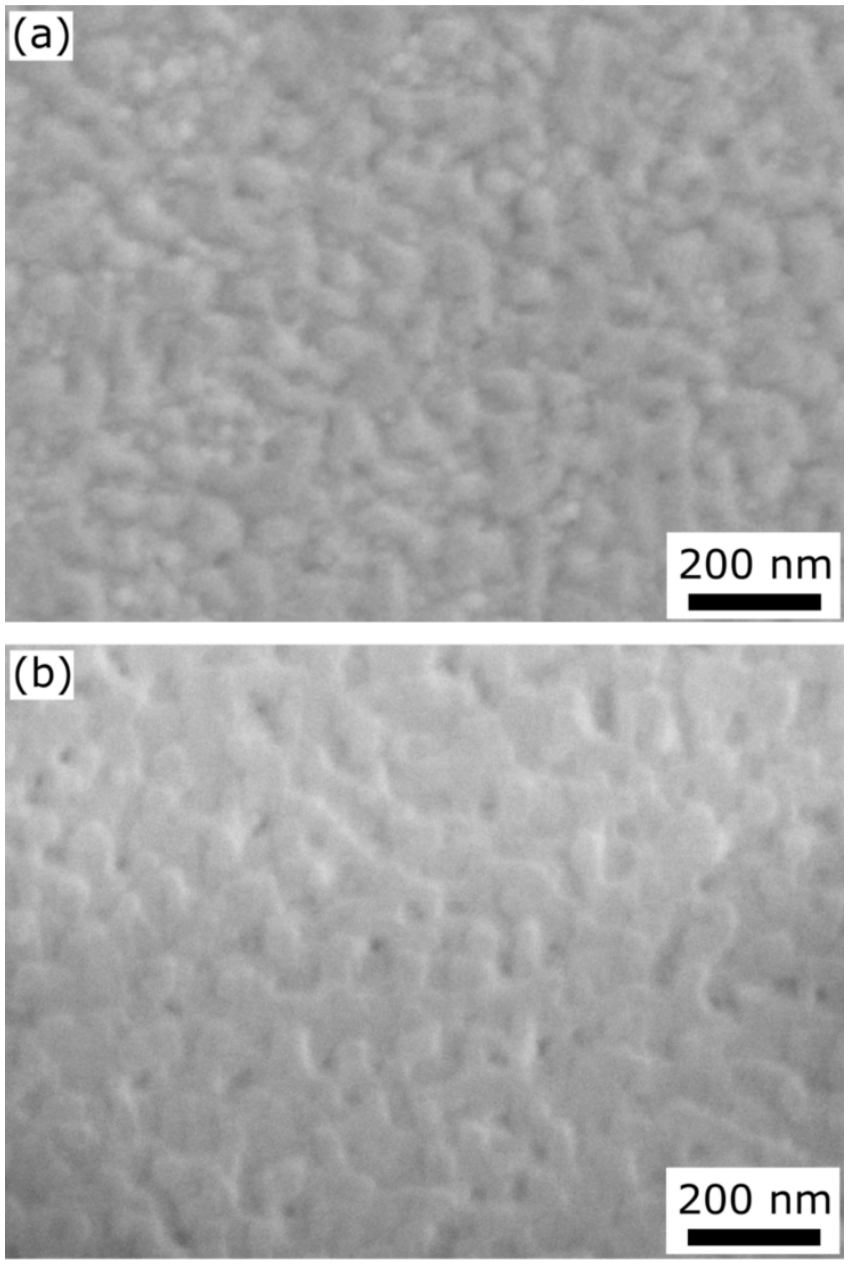

Fig. 5. SEM images taken from the filament body of the Ni-5at.\%W 2LUPS coated with two GZO layers: (a) lower plateau; (b) upper plateau.

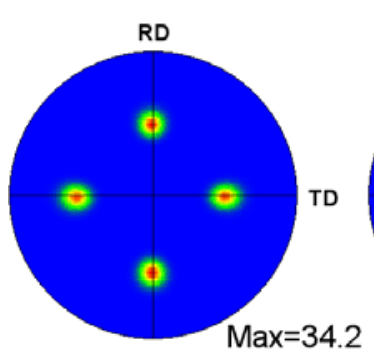

(a)

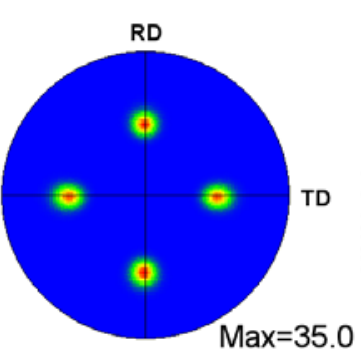

(b)
Fig. 6. $\{111\}$ pole figures showing crystallographic textures measured using the EBSD technique on the surface coated with two GZO layers: (a) lower plateau; (b) upper plateau. RD and TD correspond to the rolling direction and the transverse direction, respectively. 

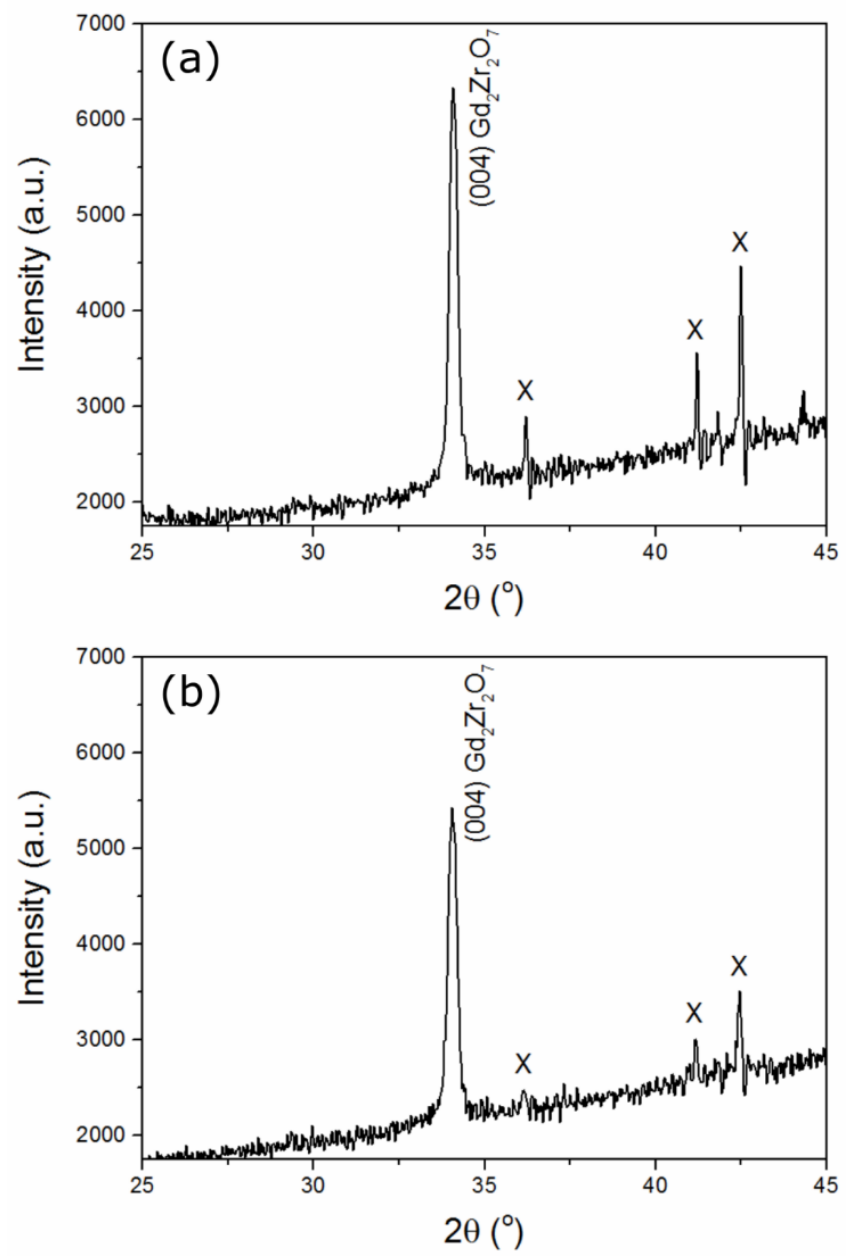

Fig. 7. $\theta-2 \theta$ XRD line profiles for the surface coated with two GZO layers: (a) upper plateau; (b) lower plateau.

The results obtained in this work suggest that the surface quality of Ni-5at.\%W 2LUPS coated with two GZO layers is appropriate for further deposition with a capping layer, for example, $\mathrm{CeO}_{2}$ and finally with a superconducting REBCO layer. Although the presence of regions incompletely covered by GZO will result in non-functional regions near the edge of the upper plateaus, the width of such regions $(\sim 50 \mu \mathrm{m})$ is expected to be similar to the width of non-superconducting grooves produced by mechanical scribing (35-55 $\mu \mathrm{m}$ [7]) and laser striation on CCs with a stabilizing copper layer (37-42 $\mu \mathrm{m}$ [8]). It is suggested that further development of $\mathrm{Ni}-5 \mathrm{at} . \% \mathrm{~W}$ 2LUPS tapes should focus on producing defect-free plateau surfaces to facilitate their full coverage by buffer and superconducting layers as well as on reducing the waviness along the wall length during etching of the lower plateaus.

\section{CONCLUSION}

A two level undercut-profile substrate can be successfully produced from a commercial cube-textured $\mathrm{Ni}-5 \mathrm{at} . \% \mathrm{~W}$ tape. The undercut length for this substrate is $2.3 \mu \mathrm{m}$. Slip lines induced by deformation during cutting of this commercial tape are observed in narrow regions near the edge of upper plateaus. Except for these regions, which are not fully covered by $\mathrm{Gd}_{2} \mathrm{Zr}_{2} \mathrm{O}_{7}$ buffer layers, the surface quality of this substrate is considered to be appropriate for dip-coating with chemicalsolution-based buffer layers.

\section{ACKNOWLEDGMENT}

The authors would like to thank P. H. Nielsen for assistance with sample preparation and metallographic analysis of the cross-section. Dr. K. Thydén is acknowledged for his help during SEM investigations.

\section{REFERENCES}

[1] E. H. Brandt and M. Indenbom, "Type-II-superconductor strip with current in a perpendicular magnetic field," Phys. Rev. B, vol. 48, 1993, Art. ID. 12893.

[2] N. Amemiya, S. Kasai, K. Yoda, Z. Jiang, G. A. Levin, P. N. Barnes, and C. E. Oberly, "AC loss reduction of YBCO coated conductors by multifilamentary structure,” Supercond. Sci. Technol., vol. 17, 2004, pp. 1464-1471.

[3] P. N. Barnes, M. D. Sumption, and G. L. Rhoads, "Review of high power superconducting generators: present state and prospects for incorporating YBCO windings,” Cryogenics, vol. 45, 2005, pp. 670-686.

[4] S. Elschner et al., "ENSYSTROB - design, manufacturing and test of a 3-phase resistive fault current limiter based on coated conductors for medium voltage application,” Physica C, vol. 482, pp. 98-104, 2012.

[5] W. Goldacker, F. Grilli, E. Pardo, A. Kario, S. I. Schlachter, and M. Vojenčiak, "Roebel cables from REBCO coated conductors: a onecentury-old concept for the superconductivity of the future," Supercond. Sci. Technol., vol. 27, 2014, Art. ID. 093001.

[6] J. Šouc, F. Gömöry, J. Kováč, R. Nast, A. Jung, M. Vojenčviak, F. Grilli, and W. Goldacker, "Low AC loss cable produced from transposed striated CC tapes,” Supercond. Sci. Technol., vol. 26, 2013, Art. ID. 075020.

[7] I. Kesgin, G. Majkic, and V. Selvamanickam, "Fully filamentized HTS coated conductor via striation and selective electroplating," Physica $C$, vol. 486, pp. 43-50, 2013.

[8] R. Nast et al., "Influence of laser striations on the properties of coated conductors,” J. Phys.: Conf. Ser., vol. 507, Art. ID. 022023.

[9] I. Kesgin, G. A. Levin, T. J. Haugan, and V. Selvamanickam, "Multifilament, copper-stabilized superconductor tapes with low alternating current loss,” Appl. Phys. Lett., vol. 103, 2013, Art. ID. 252603.

[10] A. C. Wulff et al., "Two level undercut-profile substrate for filamentary $\mathrm{YBa}_{2} \mathrm{Cu}_{3} \mathrm{O}_{7}$ coated conductors,” Supercond. Sci. Technol., vol. 28, 2015, Art. ID. 072001.

[11] A. C. Wulff, "Method for producing substrates for superconducting layers," World Patent Application, Art. ID. WO2013174380A1.

[12] S. C. Hopkins, "Full-width low AC loss coated conductor production by substrate modification,” Supercond. Sci. Technol., vol. 28, 2015, Art. ID. 090501.

[13] A. C. Wulff, Y. Zhao, O. V. Mishin, and J.-C. Grivel, "Effect of initial surface quality on final roughness and texture of annealed Ni-5at.\%W tapes coated with a $\mathrm{Gd}_{2} \mathrm{Zr}_{2} \mathrm{O}_{7}$ buffer layer," J. Supercond. Nov. Magn., vol. 25, pp. 475-479, 2011.

[14] A. C. Wulff, O. V. Mishin, and J.-C. Grivel, "Evolution of microstructure, texture and topography during additional annealing of cube-textured $\mathrm{Ni}-$ 5at.\%W substrate for coated conductors,” J. Alloy. Comp., vol. 539, pp. 161-167, 2012.

[15] U. F. Kocks and H. Mecking, "Physics and phenomenology of strain hardening: the FCC case,” Progr. Mater. Sci., vol. 48, pp. 171-273, 2003.

[16] M. P..Paranthaman et al., "Buffer Layer R\&D for YBCO Coated Conductor Composite Wires," AIP Conf. Proc. 711, 2004, pp. 645-652.

[17] A. Goyal, "Second-generation HTS conductors," 1st ed., Norwell Massachusetts, USA, 2010.

[18] P. Møller and L. P. Nielsen, “Advanced Surface Technology,” vol. 1, Møller \& Nielsen, Denmark, 2013, pp. 105-147.

[19] Y. Zhao, L. Ma, W. Wu, H.-L. Suo and J.-C. Grivel, "Study on advanced $\mathrm{Ce}_{0.9} \mathrm{La}_{0.1} \mathrm{O}_{2} / \mathrm{Gd}_{2} \mathrm{Zr}_{2} \mathrm{O}_{7}$ buffer layers architecture towards all chemical solution processed coated conductors," J. Mater. Chem. A, vol. 3, 2015, Art. ID. 13275. 